\title{
EDITORIAL
}

For reprint orders, please contact: reprints@futuremedicine.com

\section{Interprofessional pain education: the road to successful pain management outcomes}

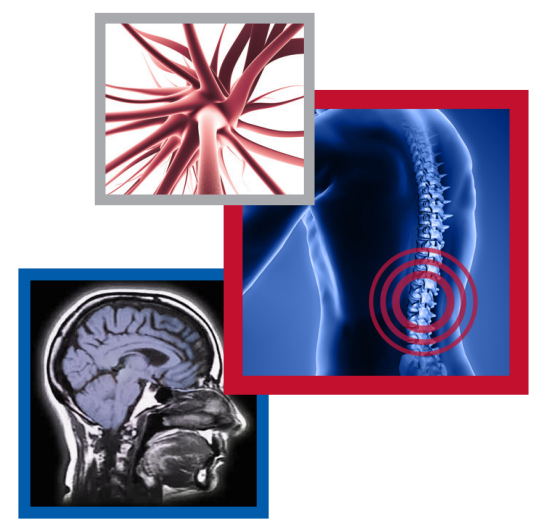

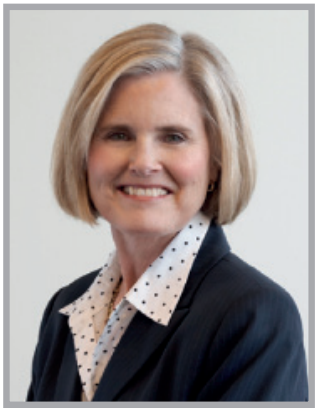
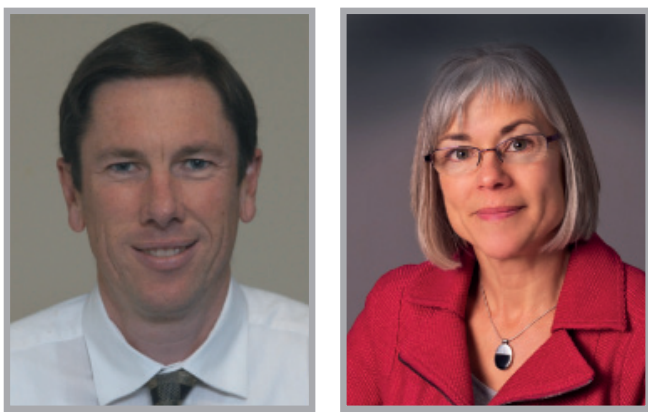

Judy Watt-Watson*1 Philip J Siddall ${ }^{2}$
Eloise Carr ${ }^{3}$
Interprofessional education (IPE) as a concept was first developed over 15 years ago by the Centre for the Advancement of Interprofessional Education [1]. More recently, the WHO reiterated the crucial role of IPE as an important step in developing collaborative practice, which has demonstrated benefits for health service, delivery and outcomes [101].

Although the importance of IPE is increasingly recognized, clarification about the meaning of this term is often required [2]. IPE has been defined as two or more professions learning with, from and about each other to improve collaboration and quality of care $[1,101]$. Traditionally, approaches to the development and implementation of curricula for health science students have been mainly intraprofessional, such as within the professions of medicine or nursing or within medical departments such as surgery, anesthesia or neurology. While the move to multiprofessional education involves different professions, the content is usually delivered in a large didactic lecture format to several professional groups with minimal interaction or sharing of roles.

As mentioned, research evidence for IPE supports positive health outcomes for patients and health systems from collaborative teams [101]. For healthcare professionals to collaborate in meeting patients' needs, they must understand each other's roles and expertise. This understanding is a necessary foundation for valuing, respecting and maximizing the contribution of other members of the team to the management of complex problems such as those for people with persistent pain. IPE fosters this understanding through small groups working together on a project, unlike multiprofessional education where students learn simultaneously but with minimal interaction. An interprofessional pain curriculum provides a common basis for different professions to learn the same language, a shared biopsychosocial conceptual framework and a basic understanding of pain mechanisms, conditions and principles of management.
"Interprofessional education (IPE) has been defined as two or more professions learning with, from and about each other to improve collaboration and quality of care."

TThe Lawrence S. Bloomberg Faculty of Nursing, Senior Fellow, Massey College, University of Toronto, 155 College Street, Suite 130, Toronto, ON, M5T 1P8, Canada

2University of Sydney, Greenwich Hospital, River Road, Greenwich, NSW, 2065, Australia

${ }^{3}$ Faculty of Nursing, University of Calgary, Professional Faculties Building, 2500 University Dr NW, Calgary, AB,

T2N 1N4, Canada

*Author for correspondence: Tel.: +1 416978 2850; Fax: +1 416978 8222; j.watt.watson@utoronto.ca

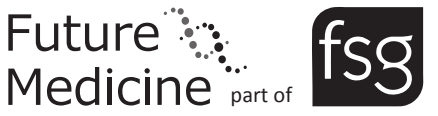




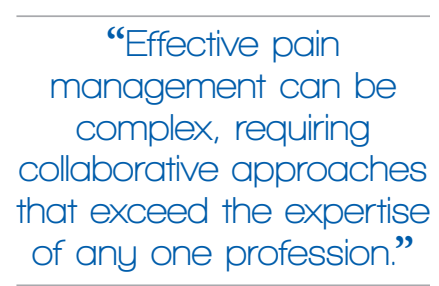

of any one profession."

\section{Collaboration \& interprofessional} education

Effective pain management can be complex, requiring collaborative approaches that exceed the expertise of any one profession. Healthcare delivery today requires competency to address the myriad of demands and in particular the management of chronic disease such as ongoing pain. Therefore, developing collaborative competencies is an important component of IPE. These include recognizing and respecting the roles, responsibilities and competencies of others in relation to one's own, and knowing when, where and how to involve these other professionals [3]. Interprofessional group opportunities allow students to learn of each other's expertise, both shared and unique, an aspect that is essential to interprofessional and/or multiprofessional pain management.

In 2010, the WHO published a landmark document The Framework for Action on Interprofessional Collaboration and Practice, which highlights the current status of interprofessional collaboration around the world and emphasizes the need for leaders of health and education to work together in preparing a 'collaborative practice-ready' health workforce [101]. The document suggests that collaborative practice involves an interprofessional team with multiple health professionals from different backgrounds who can work together with patients, families, carers and communities to deliver the highest quality of care. Working as a team to plan, manage and monitor care (interprofessional) and/or communicating/coordinating care from individual healthcare professionals (multiprofessional) results in more effective patient outcomes. The management of pain requires the effective functioning of teams to deliver care and there is evidence that the delivery of both acute [4] and chronic [5] pain services reflects this approach.

\section{Lack of pain content in prelicensure (undergraduate) curricula}

Although pain education has been identified as a strategy to improve ineffective pain management practices [6], recent evidence demonstrates the continuing lack of pain content in health science curricula, particularly for students in their first professional program (prelicensure/undergraduate/entry-to-practice) [7-9]. The International Association for the Study of Pain (IASP) has recognized the need to facilitate educational initiatives through its establishment of an Education Initiatives Working Group in 2009 with the subsequent formation of a Special Interest Group in Pain Education for IASP members in 2010.

IASP has also recognized the importance of collaboration and interprofessional education. Building on the successful uniprofessional curricula, it has recently developed an Interprofessional Pain Curriculum Outline to be available online to members and the wider community. The latter provides an outline of basic pain topics common to all professions but does not replace the uniprofessional curricula that outline additional depth in content required by each individual profession and discipline. The outline is to be used with health science students who are in their first professional program to provide shared opportunities to learn together (e.g., dentistry, medicine, nursing, occupational therapy, pharmacy, physical therapy, psychology and social work). This initiative has provided an important guide that can be implemented in a variety of ways considering the professions involved and regional needs.

Prelicensure interprofessional education can pose challenges for implementation and evaluation $[10,11]$, which may explain the focus in publications being mainly on postlicensure professionals [3,12]. However, educational initiatives have been shown to be most successful when integrated early in the socialization and educational experience of diverse professionals; negative attitudes reinforced in the undergraduate years are more challenging to change later [13]. Pedagogically, pain assessment and management provide an excellent model for interprofessional teaching and learning because of pain's prevalence across divergent groups and its potential complexity requiring interprofessional involvement. An important question to ask is the degree to which pain content is a component of required curricula in health science faculties. Two recent cross-sectional studies underline a lack of attention to this complex healthcare issue in health science curricula [7,8]. In both Canada and the UK, the content emphasis was considerably less for pain assessment, which is essential to management, compared with neurophysiology and management strategies such as pharmacology. Furthermore, Mezei and Murinson found significant gaps between recommended pain curricula and pain education content in American and Canadian medical schools [9]. 
Medicine graduates comprise a large group of future practitioners yet pain education for this medical student group was described as limited and fragmented.

\section{Pain competencies \& collaborative practice}

Establishing an expectation that pain education will be included in the prelicensure curricula is driven by the individual professional competencies and standards. These ensure that health science students have the knowledge and skills to manage pain in a way that also allows them to meet professional ethical standards [7]. However, prelicensure (undergraduate) pain competencies, including those for collaborative practice in the context of pain assessment and management, are minimal or not in place for many professions [7]. Influencing professional bodies to increase the number of required entry-to-practice pain competencies may ultimately have the greatest impact on education, including curricula, and practice.

Relevant to this context are the specific collaborative competencies suggested by Barr [3,14]. The latter includes recognizing and respecting the roles, responsibilities and competence of others in relation to one's own, and knowing when, where and how to involve these other professionals. Integrating an expectation and valuing of collaborative practice into undergraduate curricula from the beginning has been recommended to reinforce the importance of these efforts to changing practices [15]. The lack of attention to and demonstration of sufficient pain competencies at graduation limits the potential capacity for healthcare professionals to practice ethically, including as a team [16].

\section{New strategies for interprofessional pain education}

New strategies that involve all healthcare professionals are required to support changes in educational practices. Improved technology and increased access have encouraged the development of online learning and a related range of pain education learning opportunities, many of which are web-based. Regardless of the delivery method, successful outcomes from an interprofessional education experience require an interactive element that is authentic and customized [10]. Simulation in its varying forms and web-based resources are being used to enhance learning and encourage interactive reflection. To support these, authentic patient content scripts can be constructed that are situated in interprofessional complex care to highlight pain learning objectives [17]. Video vignettes can be created not only to carry the script narrative, but also to simulate real-world authenticity within the web-based environment. Underlining best practices through the use of related illustrative, visual commentaries and associated auditory explanations can facilitate knowledge translation to clinical experience. Standardized patients and other simulation models have been used in our experience to achieve interprofessional students' rehearsal and integration of complex affective and cognitive skills required to address gaps in pain knowledge and beliefs [2]. The deteriorating patient simulation model piloted successfully to improve health professionals' pain assessment skills [18] is now being trialed with undergraduate health science students.

\section{Conclusion}

Unrelieved pain, whether acute, intermittent or persistent, is a very prevalent and costly problem for people worldwide, whether they have cancer or not. Health science students receive minimal pain education despite the prevalence of persistent pain that involves one in five people worldwide [101]. Despite worldwide assertions that 'pain management is a human right', pain continues to be a problem for many people. Major gaps between evidence and clinical practices reveal a problem with significant ethical dimensions and consequences. Pain education has been identified as a strategy to improve ineffective pain management practices and interprofessional pain education aims to improve care by promoting teamwork and strengthening a shared understanding of roles between professional groups. Collaboration is essential to improve the quality of care for people with pain. One profession cannot change this prevalent complex problem alone.

\section{Financial \& competing interests disclosure}

The authors have no relevant affiliations or financial involvement with any organization or entity with a financial interest in or financial conflict with the subject matter or materials discussed in the manuscript. This includes employment, consultancies, honoraria, stock ownership or options, expert testimony, grants or patents received or pending, or royalties.

No writing assistance was utilized in the production of this manuscript.

\footnotetext{
"Improved technology and increased access have encouraged the development of online learning and a related range of pain education learning opportunities, many of which are web-based."
} 


\section{References}

1 CAIPE. Interprofessional education: a definition. United Kingdom Centre for the Advancement of Interprofessional Education (CAIPE), London, UK (1997).

2 Watt-Watson J, Hunter J, Pennefather P et al. An integrated undergraduate curriculum, based on IASP curricula, for six health science faculties. Pain 110, 140-148 (2004).

3 Barr H, Freeth D, Hammick M, Koppel I, Reeves S. Evaluations of interprofessional education: a United Kingdom review for health and social care. United Kingdom Centre for the Advancement of Interprofessional Education with the British Educational Research Association, London, UK (2000).

4 Vickers A, Bali S, Baxter A et al. Consensus statement on the anticipation and prevention of acute postoperative pain: multidisciplinary RADAR approach. Curr. Med. Res. Opin 25(10), 2557-2569 (2009).

5 Oslund S, Robinson R, Clark T et al. Long-term effectiveness of a comprehensive pain management program: strengthening the case for interdisciplinary care. Proc. (Bayl.) Univ. Med. Cent. 22(3), 211-214 (2009).

6 Sessle B. Incoming president's address: looking back, looking forward. In: Progress in Pain Research and Management, Proceedings of the 9th World Congress on Pain. Devor M, Rowbotham MC, Wisenfield-Hallin Z (Eds). IASP Press, Seattle, Austria, 9-18 (2000).
7 Watt-Watson J, McGillion M, Hunter J et al. A survey of pre-licensure pain curricula in healthscience faculties in Canadian universities. Pain Res. Manag. 14(6), 439-444 (2009).

8 Briggs E, Carr ECJ, Whittaker M. Survey of undergraduate pain curricula for healthcare professionals in the United Kingdom. Eur. J. Pain 15(8), 789-795 (2011).

9 Mezei L, Murinson B. Pain education in North American medical schools. J. Pain 12(12), 1199-1208 (2011).

10 Hammick M, Freeth D, Koppel I, Reeves S, Barr H. A best evidence systematic review of interprofessional education: BEME Guide no. 9. Med. Teach. 29, 735-751 (2007).

11 Zwarenstein M, Reeves S, Perrier L. Effectiveness of pre-licensure interprofessional education and postlicensure collaborative interventions. J. Interprof. Care 19(Suppl. 1), 148-165 (2005).

12 Reeves S, Zwarenstein M, Goldman J et al. Interprofessional education: effects on professional practice and health care outcomes. Cochrane Effective Practice and Organisation of Care Group. Cochrane Database Syst. Rev. (1), CD002213 (2008).

13 Pollard K, Miers ME, Gilchrist M. Second year scepticism: pre-qualifying health and social care students' midpoint self-assessment, attitudes and perceptions concerning interprofessional learning and working. J. Interprof. Care 19, 251-268 (2005).

14 Barr H. Interprofessional Education: Today, Yesterday and Tomorrow. Learning Support Network: Centre for Health Sciences and Practice, London, UK (2002).

15 Anderson E, Manek N, Davidson A. Evaluation of a model for maximizing interprofessional education in an acute hospital. J. Interprof. Care 20, 182-194 (2006).

16 Watt-Watson J, Peter E. The ethics of Canadian entry-to-practice pain competencies: how are we doing? Pain Res. Manag. (2012) (In Press).

17 Lax L, Watt-Watson J, Lui M et al. Innovation and design of a web-based pain education interprofessional resource. Pain Res. Manag. 16(6), 427-432 (2011).

18 McGillion M, Dubrowski A, Stremler R et al. The Perioperative Pain Assessment Skills pilot trial. Pain Res. Manag. 16(6), 433-439 (2011).

\section{- Website}

101 World Health Organization Framework for Action on Interprofessional Education and Collaborative Practice. www.who.int/hrh/resources/framework_ action/en (Accessed 26 April 2012) 